\title{
Inovação e aprendizagem independente na Educação Básica
}

\author{
Innovation and independent learning in Basic Education \\ Ronaldo Mota ${ }^{1}$ \\ ${ }^{1}$ Universidade Estácio de Sá, Rio de Janeiro, RJ, Brasil
}

\begin{abstract}
Resumo
Este artigo é sobre a possibilidade de incluir o tema atual da inovação como parte integrante do ensino básico e acerca da pertinência e possibilidade de explorar neste nível uma metodologia compatível conhecida como "aprendizagem independente". Uma exigência adicional aos processos educativos contemporâneos é a preparação de futuros profissionais e cidadãos em geral para um mundo no qual a inovação é central. Para tanto, é crucial o papel que as novas tecnologias, em especial as tecnologias digitais incluindo a internet, pode desempenhar sobre as experiências educacionais de alunos e professores ao longo de suas vizências escolares.

A principal característica da abordagem de aprendizagem independente é explorar a autonomia do educando, sendo elemento chave adotar como centro do processo de aprendizagem o aluno e como referência principal o estímulo a "aprender a aprender". Embora, a definição geral inclua a autoaprendizagem stricto sensu, de fato, na maioria dos casos, na escola regular, a integração com o currículo e o professor são os protagonistas nesta metodologia. Da mesma forma, ainda que em geral se associe o potencial uso desta abordagem com adultos, certamente é quando bem jovem que o hábito do aprender a aprender melhor se desenvolve, com mais naturalidade e pertinência.

Apresentaremos também questões essenciais associadas à terceira grande revolução educacional que tem como elementos-símbolo as tecnologias digitais e a centralidade de inovação no mundo contemporâneo, os quais estão afetando profundamente dois itens fundamentais dos processos de ensino e de aprendizagem: a forma como geramos conhecimento novos e a maneira segundo a qual os construímos pedagogicamente. Assim, caminhamos rapidamente para um cenário no qual a complexa competência digital e a vocação para inovação se agregarão em nível de importância ao domínio do conhecimento tradicional e às competências e habilidades típicas ministradas nas escolas atuais, demandando a "aprendizagem independente" como metodologia apropriada para o ensino fundamental.
\end{abstract}

Palavras-chave: aprendizagem independente, inovação, educação básica.

\begin{abstract}
This article discusses the possibility to include innovation into basic education and to explore within this education, a compatible methodology known as "independent learning". An additional requirement to contemporary educational processes is to prepare future professionals and the general public to a world where innovation is of great importance. Therefore, it is crucial the role that new technologies, especially digital technologies including the Internet, can play on the educational experiences of students and teachers throughout their school lives.

The main feature of the independent learning approach is to explore the learner's autonomy, and it is of key importance to adopt the student as the center of the learning process and, the stimulus to "learn to learn" as the main reference. Although the general definition includes self-learning stricto sensu, in fact, for most cases, within the regular school, in this methodology the protagonists are the integration with the curriculum and the teacher. Likewise, even though the potential use of this approach is, in general, associated with adults, it is at the young age that the habit of learn to learn better develops, more naturally and relevant.

We will also present essential issues associated to the third great educational revolution, symbolized by the digital technologies and the innovation's central role in the contemporary world, which are deeply affecting two key items of the teaching-learning process: the way we produce new knowledge, and the way we construct it pedagogically. So, we quickly evolve to a scenario where the complex digital competence and the vocation for innovation will match, in level of importance, the traditional knowledge and to the typical skills taught in today's schools, demanding "independent learning" as the appropriate methodology for elementary and intermediate schools.
\end{abstract}

Keywords: independent learning, innovation, basic education. 


\section{Introdução}

$\mathrm{P}$ rofessor Matthew Lipman foi um pioneiro em novas abordagens de educação para crianças. Em 1972, deixou a Universidade de Columbia transferindose para a Montclair State College para desenvolver suas ideias sobre o que veio a ser conhecido como "Filosofia para Crianças" (Lipman, 1990). Dois anos depois, ele fundou, juntamente com Ann Margaret, o Institute for the Advancement of Philosophy for Children (IAPC, em português: "Instituto para o Avanço da Filosofia para Crianças"). Posteriormente, e até sua morte em 2010, tornou-se um líder nacional e mundial no campo do pensamento crítico na área da filosofia pré-universitária e da reforma educacional. Lipman foi tornou-se conhecido no Brasil ainda na década de 1980 e o Centro Brasileiro de Filosofia para Crianças foi inaugurado em 1985 em São Paulo.

Cito o Professor Lipman porque "Filosofia para Crianças" se tornou nos Estados Unidos um movimento nacional e se espalhou pelo mundo, com organizações locais e nacionais em mais de quarenta países e associações regionais na Europa, América Latina e Austrália. O Programa de Lipman (Currículo das Novelas Filosóficas) foi traduzido para dezenas de idiomas e em 1985 foi fundado o International Council for Philosophical Inquiry with Children (ICPIC, em português: "Conselho Internacional para a Investigação Filosófica com Crianças") em Copenhagen.

O ensino de filosofia para crianças, que se tornou pauta com os estudos de Lipman, mostra a necessidade de manter a criança interrogando o mundo e o conhecimento, atenta aos movimentos do universo e não acomodada a verdades pronunciadas por adultos/professores. Manter o aluno intrigado e torná-lo pensador são objetivos da filosofia. Pode-se incluir a esses objetivos outro tema contemporâneo que tem intenção semelhante: a inovação. Como parte integrante da educação fundamental, o tema tem o intuito de manter a criança admirada com o mundo, atenta às suas modificações, disposta a pensar e criar novas possibilidades de viver nesse mundo em constante transformação. Com isso, a pertinência de explorar uma metodologia compatível e inovadora conhecida como aprendizagem independente mostra-se imprescindível. Inovação e aprendizagem independente, a exemplo de filosofia para crianças, podem e devem ser elementos progressivamente presentes no cenário da educação fundamental.

A principal característica da abordagem de aprendizagem independente é propiciar cada vez mais a autonomia ao educando, sendo elemento-chave a adoção do estímulo ao aprender a aprender, e ter o aluno como referência principal e como centro dos processos de ensino e de aprendizagem. Embora a definição geral, especialmente para adultos escolarizados, também inclua a autoaprendizagem stricto sensu, de fato, na maioria dos casos e especialmente no ensino fundamental, a escola regular, a integração com o currículo e o professor são os protagonistas nessa metodologia. Da mesma forma, ainda que em geral se associe o potencial uso desta abordagem com adultos, certamente é quando criança que o hábito do aprender a aprender melhor se desenvolve, com mais naturalidade e pertinência.

Assim, corroborando com a teoria piagetiana (Piaget, 1953), em que a ênfase é no "como aprender" (procedimento) e não no "o quê aprender" (conteúdo), a aprendizagem independente incorpora as novas tecnologias, entende que os conteúdos estão disponibilizados incessante e indiscriminadamente, e que o sujeito pode acessá-los a qualquer tempo e de qualquer lugar. A máxima "aprender a aprender" faz todo o sentido uma vez que o conhecimento elaborado é sempre provisório, é construído num determinado contexto e a qualquer tempo pode ser refutado, portanto, mais do que reter conhecimento - ênfase da escola tradicional - é preciso criar procedimentos para se buscar, avaliar o conhecimento disponível a fim de que responda ao problema daquele momento. Portanto, o papel da educação nos dias atuais é o de propiciar a construção de estruturas cognitivas que suportem procedimentos necessários para atuar no mundo contemporâneo.

\section{Inovação e construção do conhecimento}

Inovação está definitivamente em todos os lugares e progressivamente se tornando central em nossa sociedade (Mota, 2009; 2011). O conceito inicial remonta ao período da Idade Média em que significava "novidade", fruto da criatividade humana. Um longo caminho repleto de dinâmicas no seu significado até que hoje seja uma espécie de ícone em nossa sociedade. A terminologia inovação, embora utilizada nos séculos XV e XVI, permaneceu de pouco uso até o século $X X$, quando passa a ser utilizada de forma exaustiva até nossos dias.

Embora durante os séculos XIX e XX, inovação tenha se associado muito à inovação tecnológica, o conceito é bem mais amplo do que se referir estritamente a máquinas e equipamentos modernos. Alguns (Godin, 2008) preferem identificar inovação como categoria, mais do que um simples conceito, o que reflete um tipo de dialética entre realidade e linguagem, de tal forma que as mudanças e eventos dão origem a novas categorias e estas trazem mudanças no mundo; o que, por sua vez, contribui para reclarificar o significado de inovação.

Na Renascença a imitação para os artesãos era vista como boa prática, associada à novidade e à inovação, bem como à invenção propriamente (Newman, 1989). Ou seja, na época a imitação era considerada como manifestação de trabalho artístico, demandando experimentação e imaginação. Imitação, ainda que não seja inovação primária, podia e, de certa forma ainda pode, ser considerada inovação derivativa ou incremental, o que difere de simples cópia. 
Assim, o conceito de inovação sempre esteve superposto à discussão acerca da diferença entre descoberta $\mathrm{e}$ invenção. Descoberta em geral se refere a fatos ou coisas que existem previamente, enquanto invenção trata da combinação ou a manufatura de novos objetos, processos ou novas teorias sobre algo.

No século XX, com o incremento do debate sobre inovação, coube a J.A. Schumpeter (1939; 1947; 1961) escrever mais extensivamente sobre o tema, abordando-o no contexto do capitalismo enquanto um sistema de destruição e disrupção criativas permanente, sendo inovação a causa principal deste fenômeno.

Schumpeter (1961) identificava cinco tipos principais de inovação: 1. novo produto, 2 . novo processo de produção, 3. abertura de um novo mercado, 4. conquista de nova fonte de suprimentos de matérias primas, e 5 . implementação de nova forma de organização. Acerca do debate entre inovação e invenção, Schumpeter (1939) contribuiu afirmando ser possível inovar sem inventar e, da mesma forma, invenção não necessariamente significa inovação, a não ser chegando efetivamente ao atendimento de demandas.

O conceito de inovação social, ampliando o conceito original, significando avanços nas ciências sociais e reformas políticas que contribuem com o bem geral da comunidade, teve origem na segunda metade do século passado (Deutsch et al. 1986). Já neste século outras abordagens estão em curso trazendo novas terminologias como inovação aberta e novos campos como economias criativas etc., contemplando áreas até então não incluídas como inovação de marketing e organizacional.

Até recentemente um modelo linear conectando ciência, tecnologia e inovação era a maneira clássica de entender o processo que começa com o conhecimento novo, o qual pode ser um artefato tecnológico, que por sua vez pode chegar a atender demandas e como tal chegar ao mercado no sentido amplo. Assim entendido, nesse modelo ciência e inovação tinham a ver, mas via um processo principalmente mediado pela tecnologia e entes distantes, sendo inovação uma possibilidade afastada do conhecimento gerado pela pesquisa. Ou seja, inovação depende da ciência, mas a ciência não necessariamente gera inovação.

Atualmente este modelo não explica mais o que está de fato acontecendo. Inovação, que costumava ser um possível futuro ponto de chegada do processo, passou a ser também a origem compartilhada de programas de pesquisa, ajudando a conceber e modular a ciência a ser produzida. Nesse sentido, ao invés da linha reta temos um círculo, como a cobra que morde o próprio rabo. Mais do que isso, a hipótese tradicional que inovação estaria associada a gerar produtos para atendimento de demandas, embora ainda válida, hoje em dia, inovação por si só pode gerar demandas não vislumbradas antes da existência do produto.

\section{Tecnologias digitais}

Uma exigência adicional nos processos educativos contemporâneos é preparar futuros profissionais e cidadãos em geral para um mundo onde inovação é central. Para tanto, as novas tecnologias, em especial as tecnologias digitais incluindo a internet, podem desempenhar grande influência nos papéis que alunos e professores experimentam ao longo de suas vivências escolares.

Atualmente, o ambiente de aprendizagem formal vai muito além dos muros da escola, permitindo experiências educacionais sem precedentes, fazendo uso de ferramentas e oportunidades inéditas, jamais disponíveis anteriormente aos modelos tradicionais de ensino. Tais novas circunstâncias exigem um pensar profundo acerca da relação que se estabelece entre educação e tecnologia, sendo necessário superar as duas posturas: antagônicas e simplistas.

Uma dessas posturas, resultado de expectativas exageradas, acredita entusiasticamente que o acesso inédito à informação, por meio das novas tecnologias, aliadas à facilidade com os jovens delas se incorporam, por si só já seria suficiente para que educação seja universalizada e de qualidade. Outra postura, oposta à primeira, reduz as novas tecnologias a somente máquinas de uso questionável no ensino tradicional e alimentando permanentemente suspeita acerca de sua real eficácia. Ambas as posturas, ainda que compreensíveis, não trazem em sua radicalidade nenhuma contribuição razoável às potencialidades e aos enormes desafios associados. $\mathrm{Ou}$ seja, há muito espaço a ser explorado entre a aceitação acrítica de qualquer nova tecnologia, consequência de entusiasmo exagerado, e a rejeição automática, derivada de preconceito sem justificativa (Selwin, 2011).

As tecnologias digitais têm cooperado para que as relações sociais e nossos hábitos e costumes no cotidiano estejam em franca modificação, seja no trabalho, no ambiente doméstico e no acesso aos serviços em geral. Curiosamente, do ponto de vista exclusivamente educacional, as transformações ainda são incipientes, refletindo o fato que o setor da educação tem sido impactado com relativo atraso, comparado aos demais setores sociais. Ainda que já estejam disponíveis as novas tecnologias em escolas, mesmo as mais sofisticadas permitindo um nível de possibilidades e interatividade sem precedentes, a utilização em sala de aula é ainda raquítica, se comparada com o uso em outros ramos da atividade humana, fazendo com que a educação experimente estar relativamente distante da fronteira em termos de apropriação de novidades tecnológicas.

\section{Aprendizagem independente}

Sendo a autonomia do educando um conceito chave associado à metodologia de aprendizagem independente, procedimentos de forte estímulo ao estudo antes das aulas 
desempenha um papel crucial (Mota, 2013; Mota e Scott 2014). Embora seja evidente a relevância de desenvolver tal estímulo para adultos, pode, eventualmente, parecer muito mais complexo adotar tal estratégia no ensino fundamental. De fato, sendo complexo por certo não é simples e nem direto, mas nada mais importante do que tentar despertar o mais cedo possível no educando certas posturas que serão preservadas e amplificadas ao longo da vida num mundo de educação permanente em que, em certa medida, todos serão estudantes para sempre, com infinitas rupturas e sem formaturas definitivas.

Segundo Bauman (2001), na contemporaneidade já não há mais a capacidade para manter a forma alongada no tempo, não há a permanência. Não há tempo para solidificar costumes, estilos de vida, instituições, crenças, convicções. Elas mudam antes de se solidificarem, tudo é temporário, por isso, denomina os tempos atuais de modernidade líquida, sem forma, sem enraizamento, sem totalização. Tudo é provisório. A única certeza é a mudança. Daí a demanda pela formação permanente. O sujeito nunca está formado, está sempre em formação. $\mathrm{O}$ anseio pelo novo faz buscar incessantemente sua atualização que se desatualiza também permanentemente.

Aprender na escola e fora dela já faz parte da rotina da nova geração. Abordagens de ensino que se caracterizam por forte estímulo ao estudo antes da sala de aula são facilitadas pelos conteúdos embarcados em dispositivos e páginas próprias na rede de cada matéria, customizados especificamente para aquele nível educacional e dirigido àquele grupo específico de alunos. Obviamente que a devida adequação à educação básica está longe de ser simples, mas possível estimular algum nível, ainda que bem introdutório, de contato anterior ilustrativo ao conteúdo. Além do desenvolvimento da prática que estimula e força a autoaprendizagem até os seus limites superiores, a competência digital, que é muito próxima dos jovens, faz parte das habilidades formadoras de um profissional futuro apto a enfrentar os desafios de um cenário em que a inovação é a marca mais notável.

Interessante destacar que o ato de estudar antes das aulas regulares na escola em nada conflita ou diminui o papel da sala de aula e da presencialidade do professor e dos demais colegas. Ao contrário, exatamente ao fazer uso do contato anterior, em algum nível apropriado de exigência com o tema a ser estudado, permite fazer com que a dinâmica da sala de aula tenha uma qualidade diferenciada, bem como passa a representar para o professor um desafio sem precedentes. Observar igualmente que compete, de alguma forma, ao mestre a coordenação de todo o processo de aprendizagem, que começa em proporcionar instrumentais para que os alunos construam sua maneira de aprender, na orientação do auto estudo, na contribuição ao desenvolvimento do conteúdo a ser embarcado digitalmente ou, quando for o caso, no desenho da página a ser disponibilizada aos alunos.

Outras abordagens educacionais, todas elas demandando uma cuidadosa releitura e customização ao am- biente da educação fundamental, tais como mãos na massa, desenvolvimento de habilidades interpessoais e trabalhos em equipe, se incorporam perfeitamente à estratégia do estudar antes das aulas (contato ilustrativo preliminar do conteúdo) como elemento motivador e dinamizador que constituem parte essencial da metodologia de aprendizagem independente. A meta da metodologia da aprendizagem independente é formar pessoas aptas a tarefas complexas, a terem pensamento autônomo, e que sejam rapidamente adaptáveis a novas demandas, como a atual de utilização de novas tecnologias, e também preparadas para as demandas da economia contemporânea.

Educação e inovação estão fortemente conectadas, sendo que um país cuja força de trabalho não estiver devidamente preparada para os desafios de um mundo que tem na inovação o elemento diferencial mais relevante, não terá como competir globalmente. Profissionais cujas formações educacionais permitirem apenas trabalhos manuais simples e de baixa complexidade estarão totalmente deslocado, com muitas dificuldades em obter níveis de satisfação e de sucesso desejados. Consequentemente, o baixo nível educacional e as metodologias não compatíveis com as demandas do mundo contemporâneo podem limitar, de forma definitiva, as possibilidades de uma nação ter um desenvolvimento econômico e social sustentável.

Educação para inovação é um tema recente, globalizado e ainda sem respostas claras ou receitas definitivas. Os vínculos entre esses dois temas, ainda que sempre tenha existido ao longo da história, nunca teve a dimensão e a relevância que têm hoje, demandando serem explorados com extrema cautela e profundidade, com especial atenção a como o conhecimento é produzido atualmente e como ele tem sido transmitido por meio das metodologias tradicionais de ensino e de aprendizagem.

No processo de compreensão da incorporação em curso das novas tecnologias em salas de aula em todos os níveis educacionais é importante destacar as promessas não cumpridas e falsas expectativas do passado, bem como os casos de sucesso e conquistas, que caracterizaram o século XX quanto ao uso das tecnologias inovadoras em cada época tais como impresso, filme, rádio e televisão.

Sobre filmes educativos, por exemplo, alguns pioneiros como Thomas Edison, fizeram previsões no começo da década de 1920 que os filmes iriam revolucionar de tal maneira as salas de aula que estas jamais seriam as mesmas e que talvez os livros viessem a ser totalmente substituídos. Em que pese o grande sucesso que os filmes resultaram, especialmente como indústria de entretenimento, o impacto educacional foi tímido (Cuban, 1986).

Após o "fracasso" dos filmes em salas de aula, veio o rádio, o qual foi apresentado como capaz de levar conhecimento a um número sem precedentes de alunos, atingindo áreas remotas jamais exploradas educacionalmente. Ainda que casos pontuais de sucesso tenham ocorrido no mundo e no Brasil (Projeto Minerva etc.), 
o fato é que os impactos líquidos finais foram muito menores do que o esperado pelos pioneiros desse meio de comunicação.

A televisão ao longo das décadas de 1970 e 1980 passou por processo muito similar ao dos filmes educativos e do rádio. A partir dos anos de 1990 os computadores começam a ser usados, e, duas décadas depois, já estão em todas as escolas. O uso pedagógico que se faz deles ainda é muito incipiente.

Um dos pioneiros a pensar no uso de uma máquina de ensinar foi Skinner (1972). Em sua máquina, seguindo uma instrução programada, o aluno responderia aos exercícios e só progrediria se acertasse. Com isso, ele individualiza o aprendizado, pois cada aluno segue seu ritmo, continua de onde parou e o professor coordena as aprendizagens.

Não é possível pensar na educação escolar sem associá -la ao uso das tecnologias disponíveis em cada momento histórico. Elas foram e são utilizadas na vida escolar. Entretanto, com a chegada das novas tecnologias digitais e a disponibilização indiscriminada do conhecimento, a escola tem tido dificuldades para usá-las nas atividades de aprendizagem. Elas não são apenas instrumentos novos é uma nova linguagem que já assimilada desde muito cedo na nova geração. Isso faz com que um elenco de experiências sugere a necessária cautela antes de afirmar de forma peremptória que a sala de aula como nós a conhecemos ou as atividades tradicionais do professor serão afetadas de forma definitiva e radical.

Todas essas tecnologias foram incorporadas às escolas e à realidade educacional, porém, até aqui sem impactar tão profundamente como seus pensadores proclamaram em seus respectivos momentos históricos. As razões prováveis das baixas repercussões são múltiplas. Uma delas é a forte tradição das pedagogias em curso, a relativa falta de capacitação dos docentes, dificuldades frente a tecnologias que, em geral, representaram algum nível de dificuldade aos docentes, gerando uma resistência por parte deles. Contribuíram também a relativa incompatibilidade entre os currículos formais tradicionais e as potencialidades das novas tecnologias não previstas antes, bem como a introdução, em geral, das novidades tecnológicas de forma vertical e autoritária (Mota, 2008).

A somatória das experiências anteriores evidencia que as questões sociais, nas quais a educação está inserida, são, em geral, mais complexas do que meras soluções tecnológicas isoladas, atestando que as tecnologias isoladamente, por certo, não representam respostas definitivas aos nossos desafios educacionais ou sociais. As novas tecnologias digitais representam hoje a convergência das mídias utilizadas no século passado. Um equipamento contém de forma integrada as várias mídias disponíveis, é muito mais eficiente e acessível simultaneamente à possibilidade do filme, do rádio, da televisão e do computador, está plenamente integrado com o telefone, a câmera fotográfica, jogos, instrumentos de localização etc.
A plena acessibilidade acompanhada da real possibilidade de utilização a qualquer tempo e em literalmente em qualquer lugar farão com que as limitações de alcance da informação ou da relação social de outrora sejam nada mais do que lembranças de um passado próximo. Assim, ainda que razoável suspeitar de novas tecnologias, até mesmo pelo histórico recente, é inegável que as novas tecnologias digitais representam uma oportunidade ímpar de forte impacto educacional e que mantém plena aderência e compatibilidade com a metodologia de aprendizagem independente e com os estímulos necessários a preparar profissionais para o mundo da inovação.

Alunos somente poderão estar preparados para os desafios futuros se, ao longo da vida escolar da educação básica, estiverem sendo preparados para explorar suas máximas potencialidades. Para tanto, precisam adquirir conhecimentos para, sincronicamente, desenvolver uma gama de habilidades que os habilitem plenamente em tarefas necessárias tais como leitura, escrita, matemática e ciências, complementadas por outras que se mostram também necessárias, como capacidade de resolver problemas, pensamento crítico, comunicação interpessoal, colaboração e trabalho em equipe. Assim, o tradicional e o novo se completam, gerando a possibilidade de construção do conhecimento em novos padrões.

Ou seja, elementos como inovação, criatividade e ética estão mais presentes do que nunca. Como consequência, educar não está ficando mais simples, se tornou mais complexo. Temos que dar conta, além do domínio clássico cognitivo (Yeager and Walton, 2011), também dos domínios intrapessoal (abertura intelectual, ética no trabalho, consciência geral, autoconfiança, flexibilidade, iniciativa e apreciação pela diversidade) (Hoyle e Davisson, 2011) e interpessoal (trabalho em equipe, colaboração, liderança e resolução de conflitos) (Salas et al., 2011).

\section{Terceira Revolução Educacional}

Fruto da relevância do tema inovação, conjugada com o papel central que tecnologias digitais desempenham contemporaneamente, podemos dizer que estamos entrando na terceira grande revolução educacional da história da humanidade (pelo menos do mundo ocidental). Consequentemente, profundas transformações na forma de ensinar e de aprender estão em curso e grandes mudanças estão ainda por vir. Para entender melhor e ter uma dimensão da terceira revolução, importante destacar os marcos referenciais da primeira e da segunda grande revoluções educacionais que a antecederam (Mota e Scott, 2014).

A primeira grande revolução é representada pelo surgimento da escola, emblematicamente em Atenas, na Grécia Antiga, nos séculos V e IV a.C. Um marco referencial importante é o filosofo Sócrates, o qual sem 
escrever para não usar as mãos demandava que seus discípulos o acompanhassem (Mota et al., 2003). Platão, seu mais destacado seguidor, foi o responsável, juntamente com seus alunos, por compilar os pensamentos de Sócrates, bem como escrever sobre seus próprios. Além disso, fundou a Academia, símbolo melhor acabado do que seria a matriz original que norteia boa parte do que ainda hoje entendemos por escola. Aristóteles, por sua vez, foi o mais importante discípulo de Platão, tendo estudado na Academia, funda sua própria escola, o Liceu. Os três na sequência, cada qual com sua abordagem e característica, podem ser considerados os protagonistas do nascimento da instituição escola na sua forma mais preliminar.

Se o símbolo da primeira revolução pode ser considerado a escola, o símbolo da segunda se materializa no livro, tornado amplamente disponível com a invenção da imprensa por Gutemberg aproximadamente dois mil anos depois da escola, no século XV. O que também possibilitou o auto estudo, pois o educando poderia continuar a estudar longe do mestre, distante da escola e do professor, um primeiro passo para a educação a distância.

A terceira grande revolução educacional, na qual estamos imersos no seu início, tem como elemento símbolo as tecnologias digitais e o papel da inovação na sociedade contemporânea, os quais estão afetando profundamente dois elementos essenciais dos processos de ensino e de aprendizagem: a forma como produzimos conhecimento e a maneira segundo a qual o trabalhamos pedagogicamente. Caminhamos rapidamente para um cenário no qual a complexa competência digital e a vocação para inovação se agregarão em nível de importância ao domínio do conhecimento tradicional e às competências e habilidades típicas ministradas nas escolas atuais.

Alunos que estão agora na educação básica fazem parte de uma geração totalmente imersa num mundo digital, destinada a conviver com mestres oriundos de um mundo não digital, uma transição muito difícil de acompanhar, pela rapidez e pela profundidade. São cérebros que aprendem e operam diferentemente, sendo educados por educadores que provavelmente sequer sabem as novas perguntas e com prováveis dificuldades de proporcionar novas formas de aprendizagem. Não há revolução sem conflitos e nesse caso o conflito é geracional, ainda que não inédito, é de difícil solução, a não ser, provavelmente, o tempo, quando uma geração é, naturalmente, substituída pela próxima.

A natureza do processo aprendizagem está mudando rapidamente. Não se trata mais de uma atividade exclusiva da escola, nem tão pouco está restrita à tradicional faixa de idade escolar. Os espaços de aprendizagem transcenderam a escola, o tempo, a exemplo do espaço, virou qualquer, e o cenário é de educação permanente ao longo da vida.

Como manter a original motivação dos alunos ao longo da educação fundamental é uma pergunta ainda sem respostas ou com respostas incompletas. Os fatores que genericamente definem a motivação, grosso modo, se dividem em dois: forças internas e forças externas (Constanta e Maria-Madela, 2011). Aquelas fontes oriundas do engajamento motivacional dos alunos nas tarefas predominantemente por eles mesmo são denominadas intrínsecas, enquanto as fontes extrínsecas vêm de fontes externas.

Explorar oportunidades, viabilizando que os alunos participem da sensação de contribuir na escolha de alguns desafios e das metas, e o compartilhando com o mestre a emoção de ter sob controle a tarefa, fazem parte das demandas da motivação intrínseca. Dentro dessa abordagem e nessa perspectiva, o estímulo está predominantemente nas recompensas internas via aumento da autoestima, sentimento compartilhado por alunos e professores na obtenção das metas propostas (Svinicki, 2003).

Por sua vez, motivação externa inclui as fontes clássicas de retorno associadas ao "estude para o teste", recompensadas por aprovação como recompensa ou punição pela reprovação (famoso "cenoura e chicote"). Em geral, as metodologias tradicionais acreditam que os reforços no estímulo ao bom comportamento e as consequências negativas nos comportamentos não desejáveis resultam em pessoas mais aptas a enfrentarem desafios futuros. Não fosse essa a crença, essa abordagem, adotada quase genericamente, seria menos utilizada.

No entanto, contrariando o senso comum, há vários estudos apontando conclusões em direção oposta, comprovando que os alunos, na maioria das circunstâncias, reagem melhor aos estímulos intrínsecos (Deci et al. 1991; Ames e Ames, 1991; Csikszentmihalyi, 1975). Mesmo assim, em que pesem tais estudos, a maioria das escolas simplesmente os ignora e continuam fazendo como sempre fizeram.

Outros estudos que conectam como foram formados os estudantes e o sucesso no futuro exercício profissional reforçam a ideia da relevância dos mecanismos de estímulos internos (Pink, 2009). Os resultados podem ser sumarizados da seguinte forma: se estamos preparando nossos alunos para que sejam cidadãos e futuros profissionais e exerçam atividades simples e de rotina, então, os métodos tradicionais (motivação extrínseca) se mostram mesmo mais eficazes; por outro lado, se queremos preparar pessoas para problemas complexos, em que a criatividade e as habilidades de aprendizagem autônoma são essenciais, então, os estímulos internos se mostram mais apropriados.

\section{Conclusões}

A nova realidade imersa em tecnologias digitais impõe que conhecimento, no sentido amplo, se apresenta de duas formas, ao contrário da versão única anterior. Antes 
sabíamos algo ou não, de forma simples; hoje podemos saber ou podemos saber onde encontrar rapidamente a informação, tornando a questão "conhecimento" menos simples. Ou seja, na prática tecnologias digitais passam progressivamente a ser mais do que meio, tornando-se essência. O aluno passa a desenvolver uma chamada "sabedoria digital" que em certos momentos se opõe ou se complementa a tradicional "inteligência".

A aprendizagem voltada a um cenário futuro de inovação como centro demonstra um profundo processo social, no qual habilidades interpessoais contam como nunca. Nesse cenário, o professor também se modifica profundamente. Além de manter as tarefas originais de instrução (transmissão de conhecimento), a elas se somam orquestrar e estimular as potencialidades dos educandos neste universo digital de forma associada com as habilidades interpessoais e outras.

Preparar estudantes para esse cenário implica enfrentar desafios que estão chegando cada vez mais rápido, demandando tratar do tema cada vez mais cedo frente aos alunos. Seja despertando criatividade, seja no contato o quanto antes com tecnologias digitais ou na preparação a tomadas de atitudes colaborativas e estímulos ao trabalho em equipe, todos elementos compatíveis com os anos iniciais do educando. Quanto antes começamos, mais estamos falando de um mundo do trabalho mais distante e, portanto, também os preparando para profissões que sequer existem hoje, mas que certamente farão uso dos atributos que pudermos despertar o quanto antes.

Educar não está ficando mais simples; está ficando mais complexo. Sem prejuízo dos conteúdos tradicionais, incluindo letramento, matemática e gosto pela ciência, pelas artes e pelos esportes, teremos que desde cedo explorar nas crianças novas habilidades como elementos de autonomia, incorporando a abordagem de aprendizagem independente como método de induzir o aprender a aprender. Por exemplo, as atitudes que podem estimular a capacidade de tratar temas complexos podem começar tão cedo quanto o hábito de ir à escola, ou mesmo antes disso. O uso de tecnologias digitais permitem aos alunos experiências extra sala de aula, antes ou depois das aulas regulares, pode ser algo menos complicado e mais estimulante do que os educadores possam imaginar, dado estarmos falando de seres que são absolutamente nativos digitais.

Escolas, pais e mesmo o ambiente "extra escola" ensinam às crianças muitas coisas. Natural perguntar se as habilidades associadas à inovação seriam ou não ensináveis e aprendíveis e o papel do ensino fundamental nisso. A resposta é que e possível sim. Inovação, tanto quanto criatividade, bem como qualquer outro conteúdo, pode ser ensinado e aprendido, tanto se estimula quanto se reprime. No caso da escola, a metodologia adotada pode cumprir ambas as missões: preparar ou despreparar alguém, seja na vida profissional futura ou como cidadão, a enfrentar os desafios de uma sociedade emergente na qual a inovação é central para o desenvolvimento social e econômico sustentável.

Exemplo de atividade motivadora simples de inovação, aplicável às séries finais do ensino fundamental e ensino médio. Uma atividade regular semanal é selecionada, permitindo acompanhamento periódico, agregador e complementar, nos seguintes termos: a. O tema selecionado (futebol, por exemplo) permite que individualmente cada aluno se expresse sobre o tema com diferentes olhares, tais como: um desenho tentando reproduzir sua emoção, um texto que pode ser na forma de relato de fato, ficção, conto ou qualquer outra forma alternativa de manifestação sobre o tema;

b. O meio utilizado, tecnologias digitais e enviados via internet, com custo zero e possibilidades, em termos de recursos, múltiplas, tendo como resultado previsível o espanto do professor sobre o que seus alunos são capazes de fazer;

c. Estímulo ao acompanhamento colaborativo por parte dos próprios colegas; ou seja, o material produzido, sob a forma de pseudônimo não identificável, é distribuído aleatoriamente (e eletronicamente) entre os colegas, viabilizando que os comentadores ao mesmo tempo que acompanhem, avaliem e contribuam (agreguem), se for o caso; d. 0 material retornado permite ao autor agregar as contribuições e desenvolver novos caminhos ou encerrar; e. A criação de blogs (se o professor tiver dificuldades, deixe que os alunos os façam) em que as obras, individuais ou coletivas, fiquem a todos expostas; f. o professor deve estimular, sem forçar, que os alunos experimentem as formas mais variadas de manifestações, sem reprimir quem adotar uma delas como sua especial característica; g. usar este receituário como guia geral, dado que a riqueza da experimentação proporcionará surpresas que, felizmente, estas "regras" são incapazes de prever.

Este é somente um exemplo de atividade, razoavelmente simples (na verdade, ao mesmo tempo, complexa de implementar na prática; todos sabemos disso) de ser desenvolvida em sala de aula mas com elementos e tarefas extraclasse que despertam vocações e instintos inovadores, estimulam tomadas de iniciativa, trabalham com elementos de colaboração e fazem uso da tendência natural que os anos declaradamente têm pelo uso de tecnologias digitais.

Finalizando, ampliando a correta observação de Mattew Lipman (1990) que abre este artigo, há mesmo muito em comum entre as crianças, os jovens, os filósofos e os inovadores em geral: a capacidade de se maravilhar com o mundo e querer transformá-lo. Olhar com olhos de estranhamento e não de acomodação, pode fazer com que a nova geração vislumbre novos problemas e novas soluções, criando e inventando novos caminhos. A Educação Básica tem muito a contribuir com essa tarefa. 


\section{Agradecimentos}

Agradecimentos: A CAPES pela Bolsa de Estudos associada à Cátedra Anísio Teixiera no Institute of Education, University of London e a Alice Carraturi pelas pertinentes sugestões e observações, embora eventuais equívocos remanescentes sejam de minha autoria somente.

\section{Referências}

Ames, Russell, \& Ames, Carole. (1991). "Motivation and Effective Teaching." In Educational Values and Cognitive Instruction: Implications for Reform, Ed. Lorna Idol and Beau Fly Jones. Hillsdale, NJ: Erlbaum. Chapter 8, pp. 247-271.

Bauman, Z. (2001), Modernidade líquida. Rio de Janeiro, Jorge Zahar.

Constanta, M.M. e Maria-Madela, A. (2011) Intrinsic and Extrinsic Motivation - An Investigation of Performance Correlation, The Journal of the Faculty of Economics - Economic, 1, pp. 671-677.

Csikszentmihalyi, M. (1975) Beyond Boredom and Anxiety. San Francisco: Jossey-Bass.

Cuban, L. (1986) Teachers and Machines: the Classroom Use of Technology since 1920. New York: Teachers College Press.

Deci, E.L., Vallerand, R.J., Pelletier, L.G., e Ryan, R.M. (1991) Motivation and Education: The Self-Determination Perspective, Educational Psychologist, 26, pp. 325-346.

Deutsch, L. et al. (1986) Advances in the Social Sciences, 1900-1980: What, Who, Where, How, Cambridge (Mass.): Abt Books.

Godin, B. (2008) Innovation, the History of a Category. Project on the Intellectual History of Imitation. Working Paper No. 1, INRS: Quebec.

Hoyle, R.H. e Davisson, E.K. (2011) Assessment of self-regulation and related constructs: Prospects and challenges, paper prepared for the NRC Workshop on Assessment of 21st Century Skills. Available in: http://www7.nationalacademies.org/ bota/21st_Century_Workshop_Hoyle_Paper.pdf. Accessed August 2012.

Lipman, M. A filosofia vai à escola, 2ª ed. São Paulo, Summus, 1990.
Mota, R., Flores, R.Z., Sepel, L., and Loreto, E. (2003) Método Científico e Fronteiras do Conhecimento, Santa Maria-RS, CESMA Ediçoes.

Mota, R. A (2008) Universidade Aberta do Brasil. In: Educação a Distância: O Estado da Arte. Fredric Litto and Manoel Formiga (eds.), pp. 297-303. São Paulo: Pearson Prentice Hall.

Mota, R. (2009) Inovação Tecnológica: Desafios e Perspectivas. Educação Brasileira, v.31, pp. 61 - 80 .

Mota, R. (2011) O Papel da Inovação na Sociedade e na Educação. In: Sonia Colombo and Gabriel M. Rodrigues (eds.). Desafios da Sociedade Contemporânea, pp. 459-474, Porto Alegre: Artmed.

Mota, R. (2013) Exploring Integrated Independent Learning and Innovation in the Brazilian Postgraduate Programmes. A ser publicado na Revista Brasileira de Pós-Graduação/CAPES, volume 20.

Mota, R. e Scott D. (2014) Educando para Inovação e Aprendizagem Independente. Rio de Janeiro: Elsevier.

Newman, W. (1989) Technology and Alchemical Debate in the Late Middle Ages, Isis, 80, 3, pp. 423445 .

Piaget, J. (1953) The origin of intelligence in the child, New Fetter Lane, New York: Routledge \& Kegan Paul.

Pink, D.H. (2009) Drive: The Surprising Truth about What Motivates Us. Riverhead Books.

Salas, E., Bedwell, W.L, and Firre, S.M. (accessed 2012) Developing the 21st century (and beyond) workforce: A review of interpersonal skills and measurements strategies. Paper prepared for the NRC Workshop on Assessing 21st Century Skills. Available in: http://www7.nationalacdemics.org/ bota/21st_Century_Workshop_Salas_Fior_Paper. pd.

Selwyn, N. (2011) Education and Technology. Key Issues and Debates. London: Continuum Int. Publ. Group.

Shumpeter, J.A. (1939) Business Cycles: A Theoretical, Historical, and Statistical Analysis of the Capitalism Process. New York: McGraw-Hill.

Shumpeter, J.A. (1947) The Creative Response in 
Economic History, Journal of Economic History, November, pp. 149-159.

Shumpeter, J.A. (1961) The theory of economic development: An inquiry into profits, capital, credit, interest, and business cycle. Translated from German by Redvers Opie, New York: OUP.

Skinner, B. F. (1972), Tecnologia do Ensino. São Paulo: Herder e Edusp, 1972.

Yaeger. D.S. e Walton, G.M. (2011) Socialpsychological interventions in education: They're not magic, Review of Educational Research, 81, 267-301. 